\title{
Academic integrity: global context and national needs
}

\section{Taras Finikov}

\author{
Ph.D., Professor, Honorary Professor of Krakow Academy im. A. F. Modzhevsky, Krakow, Poland. \\ (C) The Author, 2017. This article is published with open access at ARMG Publishing.
}

Let's first agree on the facts, and then we argue about morality.

Samuel Butler

\begin{abstract}
The article shows the influence of transformation processes in higher education to lower academic standards, changes and deformation in ethical field of global and national higher education. We considered the genesis and modern standards of academic integrity, especially their support in the European region, the real state of the academic culture of all participants in Ukrainian educational and scientific process. Authors analyzed the role of the Law of Ukraine "On Higher Education" (2014) in creation a system to counter the further spread of academic corruption. The importance of global education community was traced to confirm the values, norms, traditions, practices and intentions that form the moral core, shape individual and collective reputation of the Ukrainian academic community.
\end{abstract}

Keywords: academic integrity, moral standards, university ethos, global education community, reputation, environment and network response.

JEL Classification: A20, A22.

The second half of the XX century was the time for radical transformation in higher education. The global system of higher education is going through a significant process: "... an academic revolution has taken place in higher education ... marked by transformations unprecedented in scope and diversity ... Arguably, the developments of the recent past are at least as dramatic as those in the 19th century when the research university evolved... The academic changes of the late 20 th and early 21 st centuries are more extensive due to their global nature and the number of institutions and people they affect" [1]. This was the evaluation of the phenomenon given by UNESCO World Conference on Higher Education in 2009.

As it was rightly pointed by T. Beecher and P. Trawler, “... the change of forces affecting modern higher education in the world led to the growth and the factors that act upon it" [2]. These include: mass character, which led to a radical increase in the number of students; economization of academic space, which leads to the growing influence of school leavers and students' requests and needs for the content and practical orientation of programs and courses; globalization, which leads to a focus on trends in the world economy, accelerated development of new information and communication technologies, creation of an international network of knowledge, acquisition by the English language of a dominant position in the distribution of scientific information [3].

This, in turn, constantly stimulates the growth of social and professional mobility of a growing population, finding new partners for the financing of higher education, increased diversification of higher education systems in most countries, new structure of scientific knowledge production, constant growth of the value of problem-based knowledge and its transdisciplinary nature.

It is obvious that such profound transformation can not help affecting the overall decline in academic standards as well as certain changes and deformation of ethical field in higher education. Its scope covers all the major players in the academic arena: students, graduate students and young researchers, leading teachers and scholars, representatives of management and education controlling bodies, customers of research products, publishers of scientific literature and periodicals, leaders of civic and professional organizations and associations, related to higher education. Systems of professional values, moral norms, internal traditions and relations with broad social environment determine the principles of cooperation in this extremely complex and diverse social network that creates and supports scientific and educational activities. 
That is why all the concept of academic integrity gains particular importance for scientific and educational community. The classic definition of the term is based on the combination of the following fundamental virtues: honesty, trust, fairness, respect and responsibility [4] and later, in 2013, it was complemented by a new, sixth - courage [5]. It should be noted that academic community came gradually to the modern understanding of the term, which was defined in the document of Center for Academic Integrity in 1999, which is a consortium of more than 200 American colleges, universities and NGOs.

As one of the starting points, perhaps, we could consider the concept of scientific ethos, proposed by Robert K. Merton in 1942. He outlined four "institutional imperatives" of science: universalism, communism, disinterestedness and organized skepticism [6]. These four imperatives were soon augmented with the fifth one - originality. In its turn, during the Cold War, "communism" was replaced with "communalism". This set of scientific moral principles became widely known by the acronym "CUDOS" (communalism, universalism, disinterestedness, originality, skepticism).

Such moral paradigm made scientific activities as a common task for all scientists who must proceed with it in the interest of mankind's general prosperity. Inevitably, it provoked a broad and long discussion, as well as the appearance of both ardent supporters and harsh critics of the approach proposed by R. Merton.

Next important step was the deep understanding of the problems of professionalization in scientific and educational activities in the late 80s of the previous century. The books by E. Abbott "The System of Professions" (1988) [7] and B. Clarke "The Academic Profession" (1987) [8] took the role of certain milestones. The first one drew attention to the ongoing conflict between preserving the old and the emergence of new professions, the latter capturing the areas that previously belonged to the former ones. It stressed such important characteristic of professionalism as a specific professional behaviour. In its turn, the book by B. Clark formulated a major sign of the academic profession - the presence of its special combination of functions: teaching, administrative and research activities. Obviously, in personal practice it looks very different, some members of the academic community prefer only one function; the other part is trying to find a balance between allocating their time and attention.

Educational and scientific policy of the European Union can serve as an example of modernization efforts focused not only on national but also on continental academic culture. A tangible manifestation of awareness of the importance of ethical dimension in profound changes in the mission as well as the structure of higher education and scientific research was holding of the International Conference on this issue in Bucharest in September 2004. It is important to emphasize that alongside with economic reasons the impact of the Bologna process was significant for Europe. It was being actively developed around at that time and stimulated a rapid reform of national educational systems in many countries of our continent. An important result of the conference was the adoption of the Bucharest Declaration on ethical values and principles of higher education in Europe [9].

The participants of the conference declared that ".. universities can not be regarded as value-free institutions. The values and ethical standards they espouse will not only have a crucial influence over the academic, cultural and political development of their academics, students and staff, but also help to shape the moral contours of society-at-large. As such, they should accept explicit responsibility and take action for promoting the highest possible ethical standards. It is not enough to espouse high ethical standards at a rhetorical level. It is crucial that such standards are respected, and put into effect, in every aspect of the work of institutions - not only through their teaching and research programmes, but also in terms of their internal governance and management and engagement with external stakeholders [9]".

"Values and Principles" of the Declaration clearly defined the role of academic ethos, culture and community, academic integrity in the teaching and learning processes, democratic and ethical governance and management, research based on academic integrity and social responsiveness.

Outlining the importance of the academic culture for each university, it was emphasized that it "... should promote actively and diligently, through mission statements, institutional charters and codes of academic conduct, those values, norms, practices, beliefs and assumptions that guide the whole institutional community towards the assertion of an ethos that is based on the principles of respect for the dignity and for the physical and psychic integrity of human beings, lifelong learning, knowledge advancement and quality improvement, inclusive education, participatory democracy, active citizenship and non-discrimination. 
The autonomy of higher education institutions, although essential for effectively discharging their historic tasks and meeting the challenges of the modern world, should not be used as an excuse for them to evade their responsibilities to wider society, acting consistently for the promotion of the public good...[10]".

In attempts to give deep and concise definition to the concept of academic integrity, the participants of the Conference centered its core values on honesty, trust, fairness, respect, responsibility and accountability. We consider it justified to give the precise wording of these basic values from the text of the Declaration:

“... 2.3. The quest for honesty should start with oneself and be extended to all other members of the academic community, avoiding systematically any form of cheating, lying, fraud, theft or other dishonest behaviors which affect negatively the quality status of academic degrees.

2.4. The trust that is mutually shared by all members of an academic community is the backbone of that climate of work that fosters the free exchange of ideas, creativity and individual development.

2.5. Ensuring fairness in teaching, student assessment, research, staff promotion and any activity related to the awards of degrees should be based on legitimate, transparent, equitable, predictable, consistent and objective criteria.

2.6. A free exchange of ideas and the freedom of expression are based on the mutual respect that is shared by all members of the academic community, regardless of their position in the hierarchy of learning and research. Without such exchange academic and scientific creativity is reduced.

2.7. Responsibilities should be shared by all members of the academic community, thus allowing for the upholding of accountability and for the free expression of attitudes and actions in the face of wrongdoing ..."[10].

The authors of the Declaration paid special attention to academic honesty and social responsibility in those researches where fundamental principles of activity were identified as intellectual freedom and social responsibility. It indicated that “... both individual researchers and groups are not only morally responsible for research processes - their choice of topics, methods of enquiry and the integrity of research - but also for research outputs. As such, they should adopt and rigorously respect codes of ethical standards that regulate their scientific research... Any code of conduct in research should include both ethical standards and enforcement procedures, thus avoiding practices of superficiality, vacuity, hypocrisy, corruption or impunity ... Scientific communities should promote worldwide cooperation and assure the intellectual and moral solidarity that is based on the values of a culture for peace and on the imperative of aiming for the welfare of mankind through sustainable development... Academic staff and researchers, individually and/or collegially, have the responsibility and the right (i) to express themselves freely on the scientific and ethical challenges of certain research projects and application of their results, and (ii) in the last resort to withdraw from those projects if their conscience so dictates" [11].

A significant milestone was the adoption of "European Charter for Researchers and the Code of Conduct for the Recruitment of Researchers"[11] in 2005. The introduction of this Charter meant the spread of principles and requirements of academic integrity beyond higher education space, focusing the attention of Member States on their compliance in the European Research Area in order "... Member States endeavour to... improve the recruitment methods and career evaluation/ assessment systems in order to create a more transparent, open, equal and internationally accepted system of recruitment and career development as a prerequisite for genuine European labour market for researchers." It was highly stressed "... to transpose these general principles and requirements within their area of responsibility into national regulatory frameworks or sectoral and/or institutional standards and guidelines (charters and / or codes for researchers)." The key emphasize was given to the fact that "... Member States consider such general principles and requirements an integral part of institutional quality assurance mechanisms by regarding them as a means for establishing funding criteria for national / regional funding schemes as well as adopting them for the auditing, monitoring and evaluation processes of public bodies"[12].

European Charter for Researchers gave a clear delineation of general principles and requirements for researchers as well as for employers and funders. This list of the first mentioned includes research freedom, ethical principles, professional responsibility, professional attitude, contractual and legal obligations, the principles of good practice in research, dissemination and exploitation of results, public engagement, relation with supervisors, supervision and managerial duties, continuing professional development. The circle of the second centered on recognition of the profession, non-discrimination, research environment, working 
conditions, stability and permanence of employment, funding and salaries, gender balance, career development, value of mobility, access to research training and continuous development opportunity, access to career advice, intellectual property rights, co-authorship, supervision, teaching, evaluation/appraisal systems, complaints / appeals, participation in decision-making bodies, recruitment.

A similar role was played by the Code of Conduct for the Recruitment of Researchers which recorded the general principles and requirements for recruitment, selection, transparency, judging merits, career breaks and recognition of mobility experience, recognition of qualifications, seniority, and postdoctoral appointments of researchers.

This detailed examination allowed to ensure duties and, to some extent, regulate the rights of personnel involved in research activities in the European Union, set a high standard for politicians and legislators of the countries seeking to join this community.

Among the most interesting documents of recent years, which can influence the modern university culture and introduce in its institutional fabric "... material practices and symbolic constructs which constitute and organize the principles of individuals and organizations' behaviour"'[13] is the Joint International Association of Universities - Magna Charta Observatory (IAU_MCO) Guidelines for an Institutional Code of Ethics in Higher Education ${ }^{17}$. This document provides a framework, a sort of charter between the main actors of university scene that forms their consent and responsibility for adherence to certain principles which are able to create organizational and moral identity. They were the following [13]:

Academic honesty and ethical behavior in research.

$>$ Equality, justice and non-discrimination.

$>$ Accountability, transparency and independence.

$>$ Critical analysis and respect for reasoned opinions;

$>$ Responsibility for the assets, resources and the environment.

$>$ Free and open transmit of knowledge and information.

$>$ Solidarity for fair treatment of international partners.

The above mentioned Guidelines shaped the place of ethics, principles and documents in the regulation of university culture, defined the basic procedures, practices and actors who take part in it, proposed the scheme for implementing institutional codes of ethics to ensure accountability of each institution of higher education to the community for providing qualitative education and conduct appropriate research, protection and promotion of a high level of academic integrity and ethical conduct.

The history of creation of the Pan-European Platform on Ethics, Transparency, and Integrity in education (ETINED) presented real understanding of the importance which is given in the European region to the significance to the construction of mechanisms of academic community inner self-regulation, its value priorities and interaction logic, including all national educational systems in the process. The idea of this initiative of Council of Europe originates from the Final Declaration of Council of Europe Standing Conference of Ministers of Education on Governance and Quality Education in Helsinki (April 2013) “..to establish a pan-European platform of exchange of information and best practices on ethics and integrity in education with special attention to the fight against corruption and fraud in education and research with a view to furthering the "Helsinki agenda for quality education in Europe"... Initiators underlined eloquently, "In presenting this Council of Europe Platform on Ethics, Transparency and Integrity in Education, it will be important to emphasize to all Member states that the Council of Europe wishes to enter a high-level Council of Europe conversation about potential general issues and ways forward, avoiding suggestions that issues only exist in particular member states (author's italics). This should be a genuinely European-wide conversation, as the relevant issues do not only affect developing and "transition" societies, but can also affect "mature" societies"[14].

The practical work was initiated in September 2013 with the baseline feasibility study, which has been prepared in November of that year. The next step was the appeal to professionals of all countries that are parties to the European Cultural Convention of the Council of Europe to respond to the specially designed online form. The analysis of responses to this questionnaire allowed developing a full feasibility study "Development of Pan-European platform on ethics, transparency and integrity in education", which was completed in February 2014. A significant part of the structure and content of the full study was defined by questions and answers of the questionnaire. This was considered important as allowed to consider the whole spectrum of 
opinions from the responses and outlined new prospects for the countries-members of the European Cultural Convention of the Council of Europe to be put in the spotlight in the creation of policy in this area of Europe. Full justification was approved in March 2014. The conducted work helped to form a working group that set out to develop Pan-European platform on ethics, transparency and integrity in education. Along with the "Basic definitions" the working group concentrated its efforts on the development of the document "Ethical principles", moving to the document "Ethical behavior of all actors in the educational process". ${ }^{21}$ Projects of these documents were approved in preparation for the Seventh Prague Forum "Towards a Pan-European platform on ethics, transparency and integrity in education", which took place on October 1-2, 2015.

The preparatory work to create a platform conducted during 2013-2016 helped to develop, thoroughly discuss and approve such basic documents as the "Ethical principles" [14], "Ethical behaviour of all actors in education" $" 23$ and form the above-mentioned platform as a network of experts from 50 countries, which are parties to the European cultural Convention of the Council of Europe. This unique forum aims to organize research, monitoring and assessment, developing on their basis practical and concise guidelines and tools, focused on the needs of Member States, teachers, students and educational community. In 2017-2018 this activity will focus on the following priorities: ethical behavior of all actors in education; academic integrity and plagiarism; recognition of qualifications; contribution to the global action against corruption; other relevant activities conducted in cooperation with other international organizations which work in the field of fight against corruption and its destructive influence upon all levels of education [15].

The above experience is the description and almost ideal practice of creating methodology to the analysis of the problem, development of tools that allows to consider broadly the range of assessments and reasons from members of the future process, focuses on the formulation of the most important basic documents, general promotion, legitimize expanded activities with using the opportunities for transnational peer network. Such practices should become a model for system-oriented activities to eradicate corruption in Ukrainian educational environment.

Modern Ukraine belongs to that group of countries, where corruption is social phenomenon, which penetrates deeply into all walks of the society. The most total appraisal of it is given in the latest research done by Transparency International "People and Corruption: Europe and Central Asia 2016". It ascertained the following:

> $56 \%$ of Ukrainian population regard corruption as one of the most serious problems of this country;

$>64 \%$ of Ukrainian population consider Ukrainian Parliament deputies as corrupted:

$>86 \%$ of Ukrainian population think that all efforts done by authority branches to fight the corruption are completely ineffective;

$>$ more than $57 \%$ of Ukrainian population think that the richest part of the society very often influences the government decision to reach their personal interests;

$>38 \%$ of Ukrainian households had to pay bribes during recent 12 months to get the social services like elementary, secondary and professional education;

$>$ only $19 \%$ of those people who had given the bribes informed the authorities and media;

Ukraine belongs to those countries where only 10 to $17 \%$ of population regards corruption as socially unacceptable [16].

In conditions of Ukrainian society, corruption, self-organization of academic environment on false moral principles, mass deviant behavior of actors and stakeholders in this sector are constant impetus for its development because of the sudden changes and uncertainties of social ideals and benchmarks, professional standards and regulations, significant loss in control of society, imbalance in the actions of state institutions of governance, weak civil society. There is a huge special literature on this issue, which is not the subject of our focused attention in this article.

Among the recent analytical works that give fairly good idea of the integrated current situation, we can name the sociologic research "The Academic Culture of Ukrainian Students: Main Factors of Formation and Development" (East-Ukrainian Foundation for Social Research in cooperation with Social and Humanitarian Research Institute of V.N. Karazin Kharkiv National University, conducted from December, 25 to July, 2015" [17]. It gives fairly consistent presentation of basic motivation for entrance and study in Ukrainian high school, mechanisms and traditions of assessment of student knowledge and their educational practices as components of academic culture, different manifestations of academic fraud, as the fundamental problem of 
domestic academic culture. The most distinct of this is the fact that $67 \%$ of students enter Ukrainian higher institutions without dominant motivation to get professional knowledge; in the process of study there is a stable tendency reorientation the majority of students from getting knowledge to getting formal attributes of education (certificates); only $14 \%$ are firmly oriented to professional work in the field of their expertise, the appalling 54\% are not going to practice their profession; $76 \%$ are involved in illegitimate team activities during exam period; $67 \%$ systematically resort to cheating as academic fraud; the majority (more than $90 \%$ ) of students plagiarize; $23 \%$ indicate that at their department there are cases of getting marks for money or services [18].

A review of various sources gives possibility to define the main groups of violation of academic virtue, which are evident in Ukrainian lecturers and researchers' activity. In the sphere of learning they are: extortion or provocation to get money, presents or personal services at students' assessment, absence of fair mark for training or qualifying works which have been plagiarized, completion in order of such works for money, forced purchase of teaching and methodological literature underestimation and compulsion to additional educational services and consultations, renovation at students' costs of equipment or purchase of different supplies. In the sphere of scientific research they are: preparation and publication of scientific, teaching and methodological texts with the help of plagiarism; falsification of experimental data, which are fundamental for scientific publications; including to authors' list those people who did not contribute to results; approval of researches or dissertations which do not possess any scientific, social or practical value; giving positive reviews or responses to the works which upon the results do not deserve such ones; getting unjustified preferences at grant assignation; unlawful abuse of the position.

It should be noted that for the recent fifteen years, the problem of academic integrity has regularly been focused by public attention, but until the last years had not stayed there for a long. Regular campaigns to deploy the fight for academic corruption changed each other with varying frequency, usually with the result of next exposure of plagiarism among the Ukrainian political and scientific elite. The result became accusatory emergence of a number of publications, most of which did not have analytical synthesis, were limited to individual personalities, and did not have any organizational, and, at times, even reputational consequences.

Some hopes were generated with the approval in 2014 of the new Law of Ukraine "On Higher Education", which is now at the stage of slow but consistent implementation. Its rules allowed starting building a system to fight the further spread of academic plagiarism by a clear statement in Article 6, Paragraph 6 that " ... detection of plagiarism in the thesis submitted for defense is the ground for refusal to award the corresponding degree. Detection of academic plagiarism in defended dissertation is the ground for annulment of the Specialized Academic Council Decision on award of a scientific degree and granting a corresponding diploma...". The main instrument was the introduction by Article 32, Paragraph 3 of relevant digital technologies that enable to identify the presence and amount of improperly plagiarized material of another author. Finally, by introducing by Article 69, Paragraph 6 of obligatory procedure to promulgate a thesis on the website of the institution, where a Specialized Academic Council was held, and the introduction by Article 6, Paragraph 6 of the system of disciplinary sanctions against university, supervisor, members of special councils and official opponents that gave positive opinions on the scientific work in which an academic plagiarism was detected [18].

If one tries to assess the general impact of the adopted law on the situation in compliance with academic integrity, it is worth mentioning its effects at all levels of higher education. At the level of the education system in general, it led to:

$>$ creating prospects for real autonomy for universities by reducing the field of regulation of the educational sphere from MEU (Ministry of Education of Ukraine);

$>$ increase the opportunities for students to influence the formation of their curriculum and participate in university management;

$>$ create real mechanisms for updating of academic management and rejuvenation the teaching staff;

$>$ improving the quality of Ukrainian scientific personnel, and as a consequence - the image of the national educational sphere here and abroad;

$>$ narrowing the field of corruption and facilitate more effective management through decentralization and distribution of regulatory and supervisory functions among different structures (Ministry of Education of Ukraine and National Agency for Quality Assurance in Higher Education).

At the level of higher education institutions it allows to introduce: 
a new mechanism for transparent elections of rectors, heads of faculties and departments, their rotation, as well as the prohibition of combining administrative positions that will give opportunity to create a new atmosphere at universities, democratize their life style and management;

$>$ reducing the workload of teachers especially, which opens the possibility for them to focus more on self-research and methodological side of the educational process;

$>$ genuine multi-aspect autonomy that can significantly reduce wasteful expenditure of time and labor and free up resources for a variety of personal and institutional development of universities, their students and staff.

At the level of relations with stakeholders of higher education it gives the chance to provide:

$>$ the involvement of various public, expert and other organizations to create a real mechanism of statepublic management of higher education.

The set of the features of the environment that actually would help to overcome the corrupt practices of universities includes:

$>$ striving for a clearer understanding of the values and attitudes regarding the specific purpose;

$>$ tendency to continuous monitoring of their activities;

$>$ attraction to emotional factors of motivation during activity;

$>$ willingness and ability to learn, improve themselves;

$>$ find and use the feedback;

$>$ confidence;

$>$ adaptability and lack of a sense of helplessness;

$>$ tendency to modeling future;

$>$ independence and critical thinking;

$>$ commitment to solving complex problems;

$>$ research environment to identify its capabilities and resources;

$>$ the ability to rely on subjective assessments and go at moderate risk;

$>$ willingness and ability to use new ideas and innovation to achieve the objectives;

$>$ policy of mutual benefit and wide perspective;

$>$ persistence;

$>$ confidence;

$>$ personal responsibility;

$>$ the ability to work together to achieve the goal;

$>$ ability to motivate others to work together to achieve this goal;

$>$ readiness to listen to others and to take into account the information which they offer;

$>$ desire for subjective evaluation of employees' personal potential;

$>$ willingness to allow other people to make their own decisions;

$>$ ability to mitigate disagreements and resolve conflicts;

$>$ tolerance on different lifestyles of others and understanding of pluralistic politics [19].

It is very important to get a clear understanding that higher education, as a certain social subsystem, operates in the environment. It is a complex of certain conditions, external forces and incentives that affect the object (individual / organization). In our opinion, it is interesting to refer to D. Ben-David's classic book "The role of the scientist in society" $(1971,1984)$ where he outlined the conditions for scientific activities. Under them, people in pursuit of science (the majority of academic community belong there) can be involved in their research without recurrent moral crises:

“... (a) Political conditions that allow social experimentation and pluralism and that contain some methods for comprehensive institutional change and review of change without recourse to violence.

(b) A permanent attempt to extend scientific thinking to human and social affairs in order to formulate the problems of rapid cognitive and social changes caused by science and to devise empirically investigable procedures for dealing with those problems.

(c) The application of the professional norms of the scientist to the social thinker, which imposes the discipline of not discarding existing tradition except on those specific points where there is a logically and empirically superior alternative. 
In societies where the first of these conditions is absent, there will be little chance for the development of social thought such as specified under (b) and (c) ... Social conditions do not generate intellectual ability and moral responsibility; they only provide the conditions for their exercise" [20].

Global education community is a community that is characterized by regular interaction, the presence of stable communication channels, high academic mobility, constant attention to the formation and preservation of individual and collective reputations, improving the mechanisms of reproduction. The pursuit of effective self-regulation, the ability to respond adequately to the demands of society is one of its basic characteristics. Academic community is one of those status-professional groups which have autonomy in the sense they constantly develop the charters in correspondence with which there was brought education, entrance check and exclusion from the professional community. They possess the definite feature of high self regulation and collective governing of group members' private interests [21].

The unity of academic culture, high level of professional ethics, following deontological values and standards are achieved with the help of developed infrastructure of international and national organizations, the renewed prominence among them being given to The International Center for Academic Integrity [22]. It was founded in 1992 as a national organization, but in 2010 it was officially renamed as The International Center for Academic Integrity what signaled about international influence and expanse of membership in this society. In 2016 its members worked in 22 countries in all continents. The Center holds annual international conferences, organizes research projects and offers mentoring services and recommendations for analysis, assessment and constructing effective strategies to include the cultivation of academic integrity into educational practices.

An important useful contribution into the international exchange of experience and further development of research in this area make scientific journals such as: Journal of Academic Ethics [23], being published since 2003 and Journal of Academic and Business Ethics [24], issued since 2009.

The first one is published by Springer Science+Business Media international publishing company, which specializes in the publication of academic journals and scholarly books. This periodical is interdisciplinary, peer-reviewed journal devoted to the consideration of ethical issues that arise in all phases of post-secondary education in the field of education, research and management. The journal, in quick orientation to build a global knowledge economy, highlights values, goals and functions of educational institutions. In addition to original research articles, short analytical reviews, letters and book reviews are also published [25].

The second edition is a body of USA Academic and Business Research Institute. It publishes original, but yet unpublished works related to the ethical problems of modern business and education. The most common themes of the articles that are connected to academic ethics are plagiarism, academic integrity, academic policies and forms of academic fraud. Typical topics of articles that focus on business ethics are corporate fraud, sexual harassment, intellectual forms of crime and legislative aspects [26].

In the modern era of rapid development of digital society particular attention should be paid to Globethics.net global network, which now unites more than 176000 individuals and institutions in 200 countries with interests in various fields of applied ethics [27]. It provides access to many resources on these issues, particularly through access to leading global digital libraries in the field of ethics, helps to establish cooperation in the research, holding conferences, publications and Internet information exchange.

Excellent opportunities for research are provided by a subdivision of the network - a global digital library on ethics (GlobeEthicsLib), which was launched in 2008; now it includes 4.5 million full-text documents and is a world leader of such libraries on ethics [28]. A similar project is being developed now - it is constructing such libraries in contiguous branches of knowledge.

Another component of the net which can be effectively used in the process of modeling new academic culture is the event of The Global Ethics Forum on Higher education Ethics in Action, which took place on 23-24 June in Geneva with 165 participants from more than 55 countries of the world. According to new strategy of Globethics.net for 2016-2020 four crucial aspects were put at the corner of attention at the conference. They are study and research, main functions of modern university, management and connection between higher education and society. The task of consolidation public trust, overcoming social, emotional and material values destruction, preserving the important forming role of higher education in the conditions of emerging commercialization and financial pressure as well as the question of development unethical tendencies in it have become the subject of leaders' attention from higher education sector, business, politics 
and religious organizations from all over the world [29].The main achievements of the Forum were summarized in a book published on its results [30].

The first publication "Ethics in Higher Education: Values-driven Leaders for the Future" (2017) in the digital periodic "Education Ethics" [31], just launched by Globethics.net series, deserves special attention. This book was created by the authors from eight countries on five continents and has got four big sections: values in higher education, responsible leadership, ethical topics in higher education, open and distance education. Concentrating attention on the most acute and actual problems of educational sector, highlighting the importance of leadership approach, introducing to analysis little known and unexplored practices from Asia and Africa singularize this work as not having analogues. The promise of the publishers to move the topic of ethics in higher education to priorities of general strategy of the net for 2016-2020 and to invite the world research community to contribute makes this publication the most interesting in the analytical sense and pragmatically useful in the practical one for developing global academic culture.

The basic contours of model to promote academic integrity and fight corruption at the local, university level can be defined on the basis of already existing practice. A good example of creating a real operating system in this direction is the experience of Curtin University (Australia). The key elements of the system include a special page devoted to this issue, at the official website of the institution, a set of guidelines and recommendations to fight plagiarism - Student guidelines for avoiding plagiarism, Student checklist to prevent plagiarism, Staff guidelines for dealing with student plagiarism, Flowchart for staff actions [32]. The next element is the clear definition of the nature and description of the typical examples of academic misconduct, which can't be admitted in university life. An important role in the formation of students' virtuous behavior plays Student Learning Center. In it students are offered a number of free educational programs that help get an idea of the available educational resources to acquire skills in writing academic and scientific texts of various difficulty levels in English, communication in classrooms, creating presentations, preparing project proposals, receiving mentor and tutor support [33].

An important part of the proposed system is multiple useful software products to facilitate the students to perform a variety of educational and research tasks. These include Turnitin program, which allows you to correlate students' texts with electronic texts in the Internet, published books, commercial databases, as well as students' written works done earlier, including Internet sites that deal in writing works to order. Another similar tool is the program EndNote, helping to test and find the necessary links to form lists of cited literature, implementing import of references from other databases [34]. It deserves a special emphasis that the whole system is built with a focus to help students, staff, creating conditions for their educational and scientific integrity of conduct, encouraging it. This very approach, instead of setting a focus on persecution and punishment, is the only correct policy which we must stick to.

Implementation practice for the Law of Ukraine "On Higher Education" (2014) brings to the foreground people and groups which on their ethical views, professional and social grounds, desires and volitional abilities are able to become the leaders of transformation process in Ukrainian higher school. Their efforts to introduce high ethic standards get regular organizational support from the Ministry of Education and Science. There have been started to develop national standards to comply with academic integrity for all group participants of educational activity, in 2016 Ukraine approved national experts and joined ETINED activity, started to implement four-year Strengthening of Academic Integrity in Ukraine Project (SAIUP) which is conducted with support of the Ministry of Education and Science and the Embassy of the United States in Ukraine, Ukrainian experts worked with OECD research to resist corruption on sector level (in higher education).

Modeling healthy academic culture, efforts to overcome existing deformations, accumulation of qualitatively new social capital provoked growing interest from Ukrainian university managers, lecturers, experienced experts in corruption resistance what have been accumulated in recent twenty years. Numerous publications in this problem field have become the subject for analyses, adaptation and application. The most prominent were the following: the results of the United Nations Development Programme "Fighting Corruption in the Education Sector: Methods, Tools and Good Practices" [35], completed in 2011, which presented the deep context, analyzed risks and spectrum of anti-corruption initiatives, possibilities of their influence and effectiveness; published in 2013, the fundamental report of Transparency international "Global Corruption Report: Education" [36], in which the topic of our research is related to Part 3. Transparency and integrity in higher education, Part 4. Tackling corruption in education - some innovative approaches, Part 5. The role of education and research in strengthening personal and professional integrity; known book of Jacques Hallak 
and Muriel Poisson "Corrupt schools, corrupt universities: What can be done?" (2007) [37], which is a kind of encyclopedia of the world situation and the impact of corruption on education sector, its distribution in the different phases of the educational process and at different levels of implementation and management of educational activities, contains many valuable recommendations for developers and managers in the field of educational policy.

Live national debate, connected to the international discussion about the possibility of further joint activities, the desire to develop a network of permanent contacts and interests, the union of individual and collective abilities of participants led to the idea of joint preparation of works, active publishing actions that would make the subject of extensive public dispute on professional higher school ethos, global practices of establishing institutions and traditions that meet the highest ethical standards, problem solving of conflict situations in institutionally regulated forms.

The modern generations of national academic community are strongly influenced by utilitarian views, which are often narrow, pragmatic and sometimes openly cynical. They regard morality as the one losing the role of social behaviour regulator. In terms of politics, economics, psychology it is defined by hypothetical imperatives that can vary greatly.

Only the most of the academic community's awareness of needs to move quickly toward the idea of establishing fair play, shaping their own action strategy, centered on the concept of categorical moral imperative, can lead to so much desired restructuring of national moral field of higher education in terms of strengthening its real autonomy.

(English text of the same name is based on the text of the Ukrainian language book published in academic honesty as the basis of sustainable development of the University / International Grace Fund "International Fund For Scientific Educational Policy”, Ed. by T. Finikov, A. Artyukhov - K .; Takson, 2016. - 234 p.)

\section{References}

1. Trends in Global Higher Education: Tracking an Academic Revolution (2009). A Report Prepared for the UNESCO 2009 World Conference on Higher Education. Philip G. Altbach, Liz Reisberg, Laura E. Rumbley. Executive Summary, Published in 2009 by the United Nations Educational, Scientific and Cultural Organization. Paris, p. iii.

2. Becher T., Trowler, P. (2001). Academic Tribes and Territories: Intellectual Enquiry and the Cultures of Disciplines, 2nd ed. Philadelphia: Open University Press. p. XIII.

3. Trends in Global Higher Education: Tracking an Academic Revolution (2009). A Report Prepared for the UNESCO 2009 World Conference on Higher Education. Philip G. Altbach, Liz Reisberg, Laura E. Rumbley. Executive Summary, Published in 2009 by the United Nations Educational, Scientific and Cultural Organization. Paris, p.iii - iv.

4. The Fundamental Values of Academic Integrity. The Center for Academic Integrity. October 1999. Retrieved from: http://www.academicintegrity.org/icai/about-4.php

5. International Center for Academic Integrity. Retrieved from: https://en.wikipedia.org/wiki/ International_Center_for_Academic_Integrity

6. This R. Merton article was republished: Merton R.K. The Normative Structure of Science // The Sociology of Science: Theoretical and Empirical Investigations Chicago: University of Chicago Press, 1973. p. 267-278.

7. Abbott, A. (1988). The System of Professions: An Essay on the Division of Expert Labor. Chicago: University of Chicago Press.

8. The Academic Profession. National, Disciplinary and Institutional Settings / B. Clark (ed.). Berkeley: University of California Press, 1987.

9. The Bucharest Declaration concerning Ethical Values and Principles for Higher Education in the Europe Region. Retrieved from: http://www.tandfonline.com/doi/abs/10.1080/03797720500083922?journal Code $=$ chee 20 doi: 10.1080/03797720500083922

10. The Bucharest Declaration concerning Ethical Values and Principles for Higher Education in the Europe Region. Retrieved from: Retrieved from: http://www.tandfonline.com/doi/abs/10.1080/ 03797720500083922? journalCode=chee20 doi: 10.1080/03797720500083922

11. The Code of Conduct for the Recruitment of Researchers. Retrieved from: https://www.sussex.ac.uk/ webteam/gateway/file.php?name=european-charter-and-code-of-conduct-2005-vitae.pdf\&site=377 
12. Friedland, R., Alford, R.R. (1991). Bringing Society Back. Symbols, Practices, and Institutional Contradictions: The New Institutionalism in Organizational Analysis. W.W. Powell, P.J. DiMaggio (eds.). Chicago: p. 243.

13. New IAU-MCO Guidelines for an Institutional Code of Ethics in Higher Education. Retrieved from: http://www.iau-aiu.net/content/new-iau-mco-guidelines-institutional-code-ethics-higher-education

14. Etined Ethical Principes. Retrieved from: https://www.coe.int//DG4/EDUCATION/etined/Etined _EthicalPrincipes_en.pdf

15. Ian Smith, Tom Hamilton (2016). ETINED Council of Europe Platform on Ethics, Transparency and Integrity in Education. Volume 2 - Ethical principles.

16. Ethics transparency integrity in education programme of activities. Retrieved from: http://www.coe.int/en/web/ethics-transparency-integrity-in-education/programme-of-activities.

17. Transparency International "PEOPLE AND CORRUPTION: EUROPE AND CENTRAL ASIA 2016. Global Corruption Barometer". Retrieved from: https://www.transparency.org/whatwedo /publication/7493

18. Academic Ukrainian culture students: the main factors shaping and development. Retrieved from: http://www.univer.kharkov.ua/images/redactor/news/2015-07-17/2015.pdf

19. Law of Ukraine "Higher Education" Retrieved from: http://zakon4.rada.gov.ua/laws/show/1556-18

20. Raven, J. (2002). Competence in modern society: identification, development and implementation p. $281-296$.

21. Ben-David, D. The role of the scientist in society. New literary review, 2014, p. 327-328.

22. Saks M. The Professions, State and the Market: Medicine in Britain, the United States and Russia 2015. Routledge, New York. Retrieved from: https://goo.gl/4gYpah

23. The International Center for Academic Integrity Retrieved from: http://www.academicintegrity.org/icai/ home.php

24. Journal of Academic Ethics: Retrieved from: http://link.springer.com/journal/10805 DOI:10.1007/s 10805-017-9273-2

25. Journal of Academic and Business Ethics. Retrieved from: http://www.aabri.com/jabe.html

26. Journal of Academic Ethics: Retrieved from: http://link.springer.com/journal/10805 DOI: 10.1007/s10805-017-9273-2

27. Online document: Retrieved from: http://www.aabri.com/jabe.html

28. Globethics library. Retrieved from: http://www.globethics.net/library/overall-search

29. Globethics conferences: Retrieved from: http://www.globethics.net/web/gef/conference-2016

30. Global Ethics Forum 2016 Higher Education - Ethics in Action: The Value of Values across Sectors (2016). Retrived from: http://www.globethics.net/documents/4289936/20165854/GE_Reports_GEF_2016_ isbn9782889311583.pdf/29bbd6ac-e3e7-43cd-b3a9-0fdd62ec5036

31. Ethics in Higher Education: Values-driven Leaders for the Future (2017). / Divya Singh, Christoph Stückelberger (Eds.) Online document: http://www.globethics.net/documents/4289936/ 20368389/GE_Education_Ethics_1_isbn9782889311644.pdf/cb24b223-3877-4fac-b871-584d8626e9d8

32. Academic Integrity. Retrieved from: http://academicintegrity.curtin.edu.au/

33. Curtin University. Life. Retrieved from: http://life.curtin.edu.au/learning-support/improve-your-skills.htm

34. Curtin Library: Retrieved from: http://libguides.library.curtin.edu.au/endnote-online

35. United Nations Development Programme. Fighting Corruption in the Education Sector: Methods, Tools and Good Practices. (2011). Retrieved from: http://www.undp.org/content/dam/undp/library/Democratic\%20Governance/IP/Anticorruption\%20Meth ods\%20and\%20Tools\%20in\%20Education\%20Lo $\% 20$ Res.pdf

36. Transparency International. Global Corruption Report: Education. (2013). Retrieved from: http://www.transparency.org/gcr_education

37. Jacques Hallak, Muriel Poisson (2007). Corrupt schools, corrupt universities: What can be done? Online document: http://unesdoc.unesco.org/images/0015/001502/150259e.pdf 